\title{
Morning basal luteinizing hormone, a good screening tool for diagnosing central precocious puberty
}

\author{
Dong-Min Lee, MD ${ }^{1,2}$, \\ In-Hyuk Chung, MD ${ }^{2}$ \\ 'Department of Pediatrics, Yonsei \\ University College of Medicine, Seoul, \\ Korea \\ ${ }^{2}$ Department of Pediatrics, National \\ Health Insurance Service Ilsan Hospital, \\ Goyang, Korea
}

Purpose: The standard method used to diagnose central precocious puberty (CPP) is the gonadotropin releasing hormone stimulation test (GnRHST). However, this test is inconvenient for children because it is time-consuming and requires multiple samples. This study aimed to determine the reliability of morning unstimulated luteinizing hormone $(\mathrm{mLH})$ level when screening for CPP, with an emphasis on the influence of diurnal variation.

Methods: This study included 160 girls with signs of early puberty (SMR 2) under 8 years of age. They were classified as CPP or non-CPP based on their standard GnRHST. The auxological, biochemical, and hormonal characteristics of subjects were retrospectively evaluated. The prognostic value of single morning unstimulated gonadotropin level was examined for use in CPP screening.

Results: Of 160 patients, 121 (75.6\%) presented with CPP, and 39 (24.4\%) were determined to be prepubertal. The $\mathrm{mLH} / \mathrm{mFSH}$ (morning unstimulated follicular stimulating hormone) ratio showed significant differences between the 2 groups $(P<0.001)$. The $\mathrm{mLH}$ was correlated with $\mathrm{GnRHST}$ variables $(r=0.532, P<0.001)$. The $\mathrm{mLH}$ cutoff point when screening for CPP was $0.22 \mathrm{IU} / \mathrm{L}$, which had sensitivity and specificity of $69.4 \%$ and $82.1 \%$, respectively. In regression analysis, bone age (BA) (odds ratio [OR], 1.018; 95\% confidence interval [CI], 0.967-1.071; $P=0.506$ ) and body mass index (BMI) $(\mathrm{OR}, 0.874 ; 95 \% \mathrm{Cl}, 0.583-1.310 ; P=0.515)$ were not significant predictors. The $\mathrm{mLH} \geq 0.22 \mathrm{IU} / \mathrm{L}$ group $(\mathrm{OR}, 9.596 ; 95 \% \mathrm{Cl}, 3.853-23.900$; $P<0.001)$ was highly suggestive of CPP.

Conclusion: In this study, single morning unstimulated luteinizing hormone had clinical efficacy for CPP screening, but BA advanced over chronological age and BMI was not useful for CPP screening.

Keywords: Precocious puberty, Gonadotropin-releasing hormone stimulation test, Gonadotropin-releasing hormone, Luteinizing hormone, Bone age

\section{Introduction}

Received: 21 June, 2018

Revised: 7 August, 2018

Accepted: 21 September, 2018

Address for correspondence:

In-Hyuk Chung, MD, PhD

Department of Pediatrics, National Health Insurance Service IIsan Hospital, 100 Ilsan-ro, Ilsandong-gu, Goyang 10444, Korea

Tel: +82-31-900-0520

Fax: +82-31-900-0343

E-mail: ped-endo@nhimc.or.kr

https://orcid.org/0000-0002-26947679
Precocious puberty (PP) in girls is classically defined as the development of secondary sexual characteristics, such as breast development, pubic hair, and menarche, before the age of 8. ${ }^{1)}$ Central precocious puberty (CPP) is caused by premature activation of the hypothalamicpituitary-gonadal (HPG) axis ${ }^{2}$ and is initiated as a result of pulsatile gonadotropin-releasing hormone (GnRH) secretion from the hypothalamus. ${ }^{3)}$

Declines in the age of pubertal onset and increases in the prevalence of PP have recently been widely reported throughout the United States and Europe. ${ }^{4)}$ In Korea, the annual incidence of CPP in girls increased significantly from 3.3 to 50.4 per 100,000 girls. ${ }^{5}$ Although visual evaluation of breast development is often used in initial screening for CPP, such evaluations can be influenced by external factors, and patients sometimes exhibit early physical changes without central activation of the HPG axis. ${ }^{6.7)}$ One of the main explanatory factors is the presence of environmental endocrine disruptors, which mimic estrogen activity and 
exert peripheral action on estrogen-dependent tissues such as breast and uterus. ${ }^{89)}$ Another commonly used measurement for diagnosis of CPP is advanced bone age (BA), which is often influenced by intra- and interobserver variance. ${ }^{10-13)}$

Objective laboratory testing is therefore required to differentiate CPP from peripheral PP. ${ }^{6}$ ) The gold standard for CPP diagnosis is the GnRH stimulation test (GnRHST), which measures serum luteinizing hormone (LH) and follicular stimulating hormone (FSH) levels after exogenous GnRH stimulation. ${ }^{7,14-16)}$ However, the GnRHST is especially inconvenient for testing children because it is time-consuming and requires multiple samples.

Previous studies have addressed the need for a simplified method to screen for CPP. Basal LH has been suggested as a beneficial measure ${ }^{17,18)}$ because $\mathrm{LH}$ secretion during early puberty presents a characteristic pulsatile pattern that is initially linked with sleep. As puberty progresses, this sleepwake difference decreases, and increased amplitude of LH pulse secretion is detected during the daytime. ${ }^{3,19-21)}$ Furthermore, early morning basal LH is more sensitive than late morning/ afternoon LH for CPP screening of girls in early stages of puberty. ${ }^{22)}$ Because the circulating half-life of LH is $80-130$ minutes, ${ }^{20)} \mathrm{LH}$ sampling should be performed within 2 hours after waking for accurate results.

We hypothesized that morning unstimulated LH (mLH) samples acquired within 2 hours of waking could distinguish pubertal from prepubertal girls. In this report, morning basal levels of LH and FSH were evaluated in a series of patients who were diagnosed with CPP. The prognostic value of $\mathrm{mLH}$ level for CPP screening was examined.

The aim of the study was to determine the reliability of single morning unstimulated $\mathrm{LH}$ as a screening measurement.

\section{Materials and methods}

\section{Patients and data collection}

Girls with signs of early puberty who visited the pediatric endocrinology outpatient clinic at National Health Insurance Service Ilsan Hospital (Goyang, Korea) between January 2015 and December 2016 were retrospectively reviewed. The inclusion criterion was breast development of Tanner stage II or more before the age of 8 years. Patients with peripheral PP, chronic illness, and history of long-term medication were excluded. A total of 160 girls were included in the study, which was approved by the Institutional Review Board of National Health Insurance Service Ilsan Hospital (approval number: SUYON 2014-169).

\section{Methods}

A total of 160 girls with early breast development underwent $\mathrm{mLH}$ and morning unstimulated FSH (mFSH) sampling before 8:30 AM (within 2 hours after waking up) considering LH diurnal variation.

Patients were divided into 2 groups according to the results of GnRHST performed 1 week after basal morning LH sampling. Serum samples for LH and FSH were drawn immediately before administration of $100 \mu \mathrm{g}$ of GnRH. After GnRH injection, blood samples for LH and FSH were collected at 30, 45, and 60 minutes. Peak LH concentration $\geq 5 \mathrm{IU} / \mathrm{L}$ on GnRHST was considered to indicate CPP. Girls with lower values were regarded as prepubertal.

Clinical data were obtained at the time of the visit, such as height, body weight, body mass index (BMI), chronological age (CA), BA, and results of laboratory analyses. Height was measured using a wall mounted stadiometer (Holtain Ltd., Pembrokeshire, UK), while BMI was calculated as weight divided by height ${ }^{2}$. BA was determined using the Greulich and Pyle method. ${ }^{23,24)}$ Electrochemiluminescence immunoassay (Roche Diagnostics GmbH, Cobas e602, Manheim, Germany) was used to determine LH and FSH concentrations. The intraassay coefficient of variation $(\mathrm{CV})$ values for $\mathrm{LH}$ were $1.2 \%, 0.7 \%$, and $0.9 \%$ at levels of $6.15,92.2$, and $164 \mathrm{mIU} / \mathrm{mL}$, respectively. The corresponding inter-assay $\mathrm{CV}$ values were $2.0 \%, 1.6 \%$, and $2.2 \%$ at levels of $5.81,89.1$, and $159 \mathrm{mIU} / \mathrm{mL}$, respectively. The intra-assay CV values of FSH were 2.6\%, 2.8\%, and 2.5\% at levels of $5.97,54.4$, and $178 \mathrm{mIU} / \mathrm{mL}$, respectively. The corresponding inter-assay CV values were $3.6 \%, 3.7 \%$, and $4.5 \%$ at levels of 5.33 , 45.9 , and $229 \mathrm{mIU} / \mathrm{mL}$, respectively. The lower detection limits of LH and FSH were $0.1 \mathrm{IU} / \mathrm{L}$ and $0.1 \mathrm{IU} / \mathrm{L}$, respectively.

\section{Data and statistical analysis}

SAS ver. 9.4 (SAS Inc., Cary, NC, USA) was used for statistical calculations. Associations between continuous variables were evaluated using Pearson correlation coefficient. Data are expressed as mean \pm standard deviation for continuous variables and median with range for categorical variables. Student $t$-test was used to compare groups, and $P<0.05$ was considered statistically significant. To identify independent predictors of CPP, multivariate logistic regression analysis was performed after adjustment for BA-CA and BMI. Receiver operating characteristic (ROC) curves were used to assess the cutoff level of LH. Sensitivity and specificity at each level of basal LH were evaluated, and the area under the curve (AUC) was measured. Youden's J index, defined as ([sensitivity+specificity]-1), was used to determine the optimal gonadotropin cutoff point from the ROC curve for each assay to discriminate girls with CPP from prepubertal girls. ${ }^{25)}$

\section{Results}

\section{Baseline characteristics}

A total of 160 patients were retrospectively analyzed. Auxological and biochemical characteristics of subjects are displayed in Table 1. Among 160 girls, 121 (75.6\%) presented with CPP and 
39 (24.4\%) were determined to be prepubertal after GnRHST. Mean CA was $7.87 \pm 0.74$ years in the CPP group and $7.74 \pm 0.75$ years in the prepubertal group $(P=0.330)$. Mean BA was $10.27 \pm 0.09$ years in the CPP group and $10.01 \pm 0.18$ years in the prepubertal group $(P=0.220)$. The difference between $C A$ and BA was $1.40 \pm 0.74$ years in the CPP group and $1.25 \pm 0.72$ years in the prepubertal group $(P=0.277)$. No significant differences were observed between the 2 groups regarding $\mathrm{CA}$, BA, height, weight, and BMI.

The $\mathrm{mLH}(1.01 \pm 1.81 \mathrm{IU} / \mathrm{L}$ in the CPP group and $0.21 \pm 0.28$ $\mathrm{IU} / \mathrm{L}$ in the prepubertal group, $P<0.001), \mathrm{mFSH}(3.93 \pm 2.06$ $\mathrm{IU} / \mathrm{L}$ in the CPP group and $2.39 \pm 1.43 \mathrm{IU} / \mathrm{L}$ in the prepubertal group, $P<0.001)$, and $\mathrm{mLH} / \mathrm{mFSH}$ ratio $(0.21 \pm 0.25$ in the CPP group and $0.08 \pm 0.05$ in the prepubertal group, $P<0.001)$ showed significant differences between the 2 groups.

\section{Relationship between morning unstimulated $\mathrm{GnRH}$ variables and $\mathrm{LH}$ level at 30 minutes after $\mathrm{GnRH}$ stimulation test}

Pearson correlation coefficient was used to measure how strong a relationship is between unstimulated morning GnRH variables and LH level at 30 minutes after GnRHST. The correlation coefficient of $\mathrm{mLH}, \mathrm{mFSH}$, and $\mathrm{mLH} / \mathrm{mFSH}$ ratio presented was $0.53(P<0.001), 0.31(P<0.001)$, and 0.57 $(P<0.001)$, respectively (Table 2$)$.

Table 1. Comparison of auxological and biochemical characteristics between central precocious puberty and non-CPP group

\begin{tabular}{|c|c|c|c|c|}
\hline Characteristic & Total & CPP & Prepubertal & $P$-value \\
\hline No. of subjects & $160(100)$ & $121(75.6)$ & $39(24.4)$ & \\
\hline CA (yr) & $7.84 \pm 0.75$ & $7.87 \pm 0.74$ & $7.74 \pm 0.75$ & 0.330 \\
\hline$B A(y r)$ & $9.31 \pm 0.11$ & $10.27 \pm 0.09$ & $10.01 \pm 0.18$ & 0.220 \\
\hline$B A-C A(y r)$ & $1.36 \pm 0.74$ & $1.40 \pm 0.74$ & $1.25 \pm 0.72$ & 0.277 \\
\hline Height z-score & $0.00 \pm 1.00$ & $0.05 \pm 1.01$ & $-0.15 \pm 0.96$ & 0.269 \\
\hline Body weight z-score & $0.00 \pm 1.00$ & $0.00 \pm 0.95$ & $0.00 \pm 1.16$ & 0.984 \\
\hline $\begin{array}{l}\text { Body mass index } \\
z \text {-score }\end{array}$ & $0.00 \pm 1.00$ & $-0.03 \pm 0.92$ & $0.11 \pm 1.22$ & 0.506 \\
\hline mLH (IU/L) & $0.81 \pm 1.61$ & $1.01 \pm 1.81$ & $0.21 \pm 0.28$ & $<0.001$ \\
\hline $\mathrm{mFSH}(\mathrm{IU} / \mathrm{L})$ & $3.56 \pm 2.04$ & $3.93 \pm 2.06$ & $2.39 \pm 1.43$ & $<0.001$ \\
\hline $\mathrm{mLH} / \mathrm{mFSH}$ ratio & $0.18 \pm 0.23$ & $0.21 \pm 0.25$ & $0.08 \pm 0.05$ & $<0.001$ \\
\hline
\end{tabular}

Values are presented as number (\%) or mean \pm standard deviation. CPP, central precocious puberty; $\mathrm{CA}$, chronological age; $\mathrm{BA}$, bone age; $\mathrm{mLH}$, morning unstimulated luteinizing hormone; $\mathrm{mFSH}$, morning unstimulated follicular stimulating hormone.

Table 2. Coefficient of correlation by Pearson method between morning unstimulated Gonadotropin-releasing hormone (GnRH) variables and LH level at $\mathbf{3 0}$ minutes after $\mathrm{GnRH}$ stimulation test

\begin{tabular}{lcc}
\hline Variable & Correlation coefficient & $P$-value \\
\hline $\mathrm{mLH}$ & 0.532 & $<0.001$ \\
$\mathrm{mFSH}$ & 0.310 & $<0.001$ \\
$\mathrm{mLH} / \mathrm{mFSH}$ ratio & 0.574 & $<0.001$ \\
\hline
\end{tabular}

$\mathrm{mLH}$, morning unstimulated luteinizing hormone; $\mathrm{mFSH}$, morning unstimulated follicular stimulating hormone.

\section{ROC analysis}

ROC curves were built to evaluate the sensitivity and specificity of LH, and the AUC was measured. The AUC of mLH was 0.757 (95\% CI, 0.684-0.831). The optimal cutoff value of $\mathrm{mLH}$ to discriminate between girls with and without CPP was $0.22 \mathrm{IU} / \mathrm{L}$, which had a specificity of $82.1 \%$ and a sensitivity of $69.4 \%$ (Fig. 1).

\section{Logistic regression analysis}

In univariate logistic regression analysis, $\mathrm{mLH}, \mathrm{mFSH}$, and

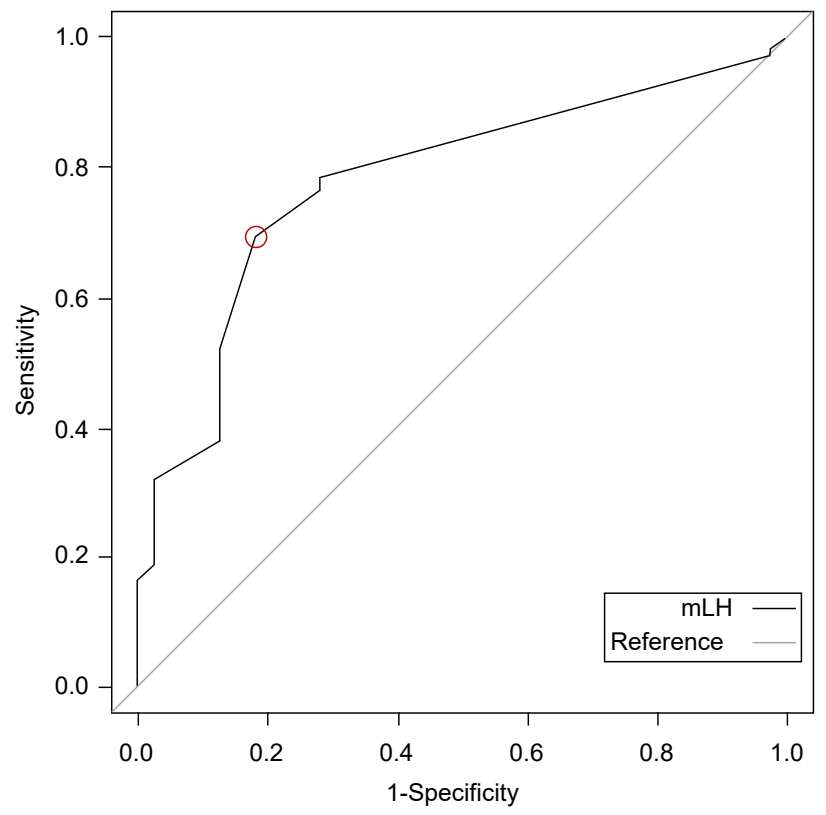

Fig. 1. Receiver operator characteristic curve of various thresholds for morning unstimulated luteinizing hormone levels (area under the curve, 0.757; 95\% confidence interval, 0.684-0.831) for predicting central precocious puberty. $\mathrm{mLH}$, morning unstimulated luteinizing hormone.

Table 3. Univariate logistic regression analysis of factors affecting the pubertal response of the gonadotropin-releasing hormone stimulation test

\begin{tabular}{lcr}
\hline \multirow{2}{*}{ Variable } & \multicolumn{2}{c}{ Univariate analysis } \\
\cline { 2 - 3 } & OR $(95 \% \mathrm{Cl})$ & -value \\
\hline CA & $1.02(0.98-1.06)$ & 0.330 \\
BA & $1.02(0.99-1.05)$ & 0.220 \\
BA-CA & $1.02(0.98-1.07)$ & 0.276 \\
Height z-score & $1.03(0.98-1.08)$ & 0.269 \\
Weight z-score & $1.00(0.95-1.06)$ & 0.984 \\
Body mass index z-score & $0.94(0.81-1.09)$ & 0.438 \\
mLH & $17.02(2.80-103.68)$ & 0.002 \\
mFSH & $1.77(1.33-2.35)$ & $<0.001$ \\
mLH/mFSH ratio & Infinit $(26.28-$ infinit $)$ & 0.003 \\
\hline OR, Odds ratio; Cl, confidence
\end{tabular}

$\mathrm{OR}$, odds ratio; $\mathrm{Cl}$, confidence interval; $\mathrm{CA}$, chronological age; $\mathrm{BA}$, bone age; $\mathrm{mLH}$, morning unstimulated luteinizing hormone; $\mathrm{mFSH}$, morning unstimulated follicular stimulating hormone. 
$\mathrm{mLH} / \mathrm{mFSH}$ ratio were significantly correlated with GnRHST results (Table 3). With these variables, multiple logistic regression analysis was performed. In a multiple logistic regression analysis adjusted by $\mathrm{BA}-\mathrm{CA}$ and $\mathrm{BMI}, \mathrm{mLH} \geq 0.22 \mathrm{IU} / \mathrm{L}$ was statistically associated with CPP (odds ratio, 9.60; $P<0.001$ ). The $\mathrm{mLH} \geq 0.22$ IU/L is considered a significant predictor of positive GnRHST $(P<0.001)$ (Table 4).

\section{Associations between FSH, BA-CA, and positive predictive values for subgroup analysis}

In girls with $\mathrm{mLH}<0.22 \mathrm{IU} / \mathrm{L}(\mathrm{n}=68)$, the probability of positive response after GnRHST increased with increased $\mathrm{mFSH}$, and the probability of positive response after GnRHST increased with increasing difference between $\mathrm{BA}$ and CA. The $\mathrm{mLH} \geq 0.22 \mathrm{IU} / \mathrm{L}$ itself showed over 0.9 probability of positive response after GnRHST (Figs. 2, 3).

Table 4. Multiple logistic regression analysis of factors affecting the pubertal response of the gonadotropin-releasing hormone stimulation test

\begin{tabular}{lcc}
\hline \multirow{2}{*}{ Variable } & \multicolumn{2}{c}{ Multivariate analysis } \\
\cline { 2 - 3 } & OR $(95 \% \mathrm{Cl})$ & P-value \\
\hline $\mathrm{mLH}<0.22 \mathrm{IU} / \mathrm{L}$ & 1 & \\
$\mathrm{mLH} \geq 0.22 \mathrm{IU} / \mathrm{L}$ & $9.596(3.853-23.900)$ & $<0.001$ \\
\hline
\end{tabular}

$\mathrm{OR}$, odds ratio; $\mathrm{Cl}$, confidence interval; $\mathrm{mLH}$, morning unstimulated luteinizing hormone.

Adjusted by bone age-chronological age (yr) and body mass index.

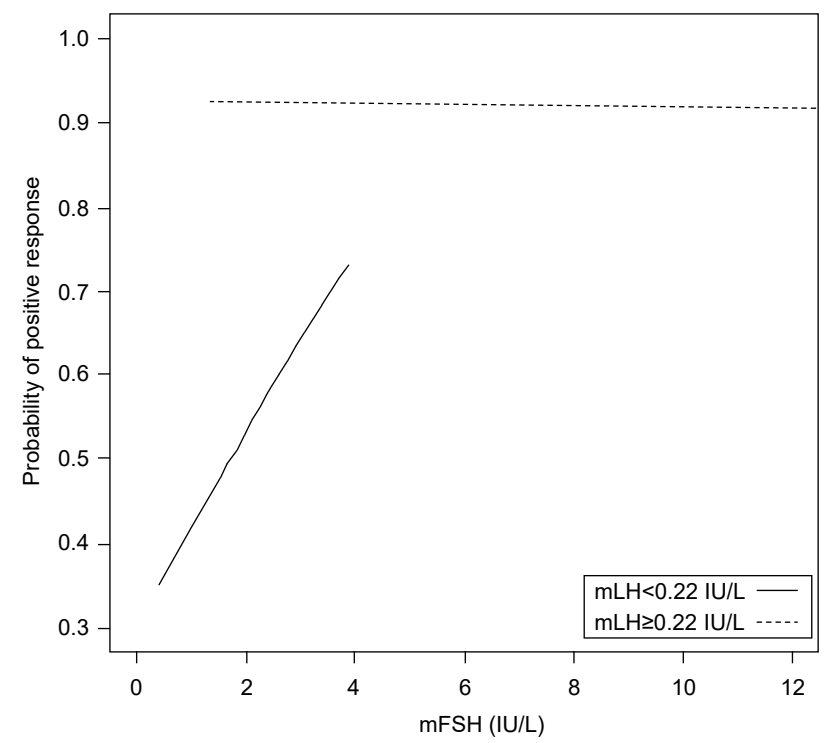

Fig. 2. Probability of positive response after gonadotropin-releasing hormone stimulation according to morning unstimulated luteinizing hormone and morning unstimulated follicular stimulating hormone. $\mathrm{mLH}$, morning unstimulated luteinizing hormone; $\mathrm{mFSH}$, morning unstimulated follicular stimulating hormone.

\section{Discussion}

CPP has recently increased in prevalence worldwide and can cause several adverse effects. CPP leads to early closure of epiphyses, which results in decreased final height. ${ }^{26)}$ Girls with CPP are at higher risk of psychological problems, reproductive tract cancers, and development of metabolic syndrome later in life. ${ }^{27)}$ Therefore, early detection and treatment of girls with CPP is important to improve their physical and mental health. However, the diagnosis of PP is challenging for clinicians. The diagnostic work-up of PP is difficult because pubertal timing is influenced by complex interactions among genetic factors, nutritional factors, environmental hormone-like compounds, and socioeconomic characteristics. ${ }^{28-31)}$

Although it is the current standard method for CPP diagnosis, GnRHST is inconvenient for pediatric patients. Therefore, initial clinical and physical examinations are generally used to screen patients with signs of early puberty. Onset of breast development (Tanner stage B2) is considered the first sign of $\mathrm{PP}$ in girls. ${ }^{32)}$ However, the presence of glandular breast tissue is difficult to assess in obese girls, and it is not easy to determine whether its development is due to GnRH - dependent activation of the HPG axis or merely represents a benign variant such as premature thelarche (PT). Diagnosis of PT has increased because of increased physician awareness, the possible influence of endocrine disruptors, and secular trends toward earlier breast development. ${ }^{33)}$

Other than breast development, another clinically useful cue for diagnosis of CPP is BA. CPP is associated with accelerated growth, advanced $\mathrm{BA}$, and early closure of epiphyses. If $\mathrm{BA}$ is advanced more than 2SD (standard deviation) relative to CA,

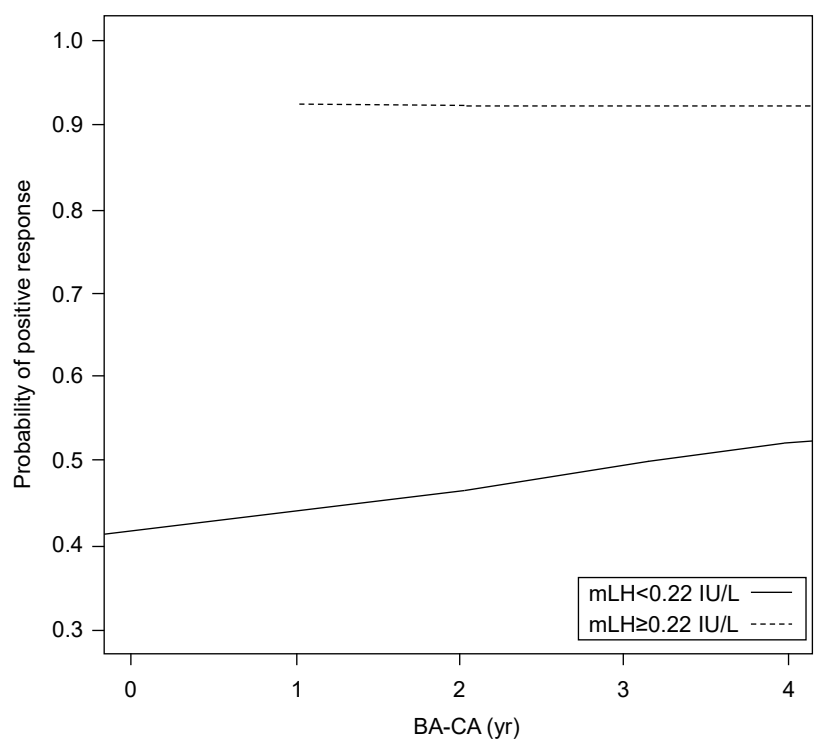

Fig. 3. Probability of positive response after gonadotropin-releasing hormone stimulation according to morning unstimulated luteinizing hormone and difference between chronological age (CA) and bone age (BA). $\mathrm{mLH}$, morning unstimulated luteinizing hormone. 
it is unlikely that a child exhibits a normal variant of pubertal development. ${ }^{34)} \mathrm{BA}$ is therefore frequently used to evaluate CPP patients in clinics. However, skeletal maturation might not be related to the age of pubertal onset. ${ }^{35)}$ Moreover, several studies have highlighted the influence of intra- and interobserver variance on BA measurements. ${ }^{10-13)}$ In the present study, BA and BA advancement were not associated with positive response after GnRHST.

Basal LH levels could be a useful screening tool, as an increase in gonadotropin levels is the first measurable step in the pubertal sequence of events. ${ }^{18)}$ Previous studies reported that basal LH levels were useful for screening girls with suspected CPP. Pasternak et al. ${ }^{18)}$ suggested that a single basal LH cutoff value of $0.1 \mathrm{IU} / \mathrm{L}$ had specificity of $94.7 \%$ and sensitivity of $64.4 \%$, which may be adequate to confirm but not refute the presence of CPP. Lee et al. ${ }^{17)}$ reported that elevated basal LH and basal LH to FSH ratio were significant predictors of positive response during GnRHST. The basal LH cutoff value was 0.1 IU/L, which resulted in $56.4 \%$ sensitivity and $88.4 \%$ specificity. The cutoff point of basal LH to FSH ratio was 0.04 , which had sensitivity $54.4 \%$ and specificity $93.7 \%$. Houk et al. ${ }^{36)}$ estimated basal LH level using 2 chemiluminescent assays (Delfia, Wallac Oy, Turku, Finland; Architect, Abbott Park, IL, USA). Basal LH level was adequate to diagnose CPP in $>90 \%$ of girls in their sample. In the Delfia assay, a basal LH cutoff value of $0.83 \mathrm{U} / \mathrm{L}$ had sensitivity of $93 \%$ and specificity of $100 \%$. In the Architect assay, a cutoff value of $1.05 \mathrm{U} / \mathrm{L}$ had sensitivity of $100 \%$ and specificity of $100 \%$.

In our study, tests were conducted within 2 hours after waking up for more accurate detection of early puberty. LH secretion during early puberty shows a circadian pattern due to nocturnal gonadotropin secretion, ${ }^{37)}$ which results in decreased pulsatile LH secretion after waking. The $\mathrm{mLH}$ is also more sensitive than late morning/afternoon LH for screening girls in the early stages of puberty. ${ }^{22)}$ Because the circulating half-life of LH is $80-130$ minutes, ${ }^{20)}$ random daytime measurements of gonadotropins are likely to be incorrect. Thus, we emphasize that diurnal variation should be considered when evaluating children for PP, especially children in the early stages of puberty.

Our results demonstrate a strong correlation between the results of tests using single basal morning unstimulated $\mathrm{LH}$ and GnRHST. Basal LH $\geq 0.22$ IU/L was sufficient for CPP screening, with $69.4 \%$ sensitivity and $82.1 \%$ specificity. Thus, $\mathrm{mLH}$ level of $\geq 0.22 \mathrm{IU} / \mathrm{L}$ can predict positive GnRHST, and CPP is more likely to be diagnosed. GnRHST or additional assessments should be considered for these girls to confirm CPP. In girls with $\mathrm{mLH}<0.22 \mathrm{IU} / \mathrm{L}$, the probability of positive response after GnRHST increased as mFSH increased and the difference between BA and CA increased. Thus, in this group, $\mathrm{mFSH}$ and BA measurement could be helpful for predicting positive response to GnRHST. However, girls with $\mathrm{mLH} \geq 0.22 \mathrm{IU} / \mathrm{L}$ did not exhibit increased likelihood of positive GnRHST response according to these variables. By itself, $\mathrm{mLH} \geq 0.22 \mathrm{IU} / \mathrm{L}$ might be sufficient to indicate high probability of positive response to GnRHST.
Findings for girls with mLH less than 0.22 IU/L suggest that the HPG axis is less likely to be involved in pubertal changes; therefore, it may be easier to observe physical evidence of early puberty than to perform immediate GnRHST. However, this single parameter is not definitive for diagnosis of CPP because it is only one of several helpful screening tools. Laboratory and physical examination results may also be inconsistent. Although $\mathrm{mLH}$ is a useful parameter for CPP screening, pediatric endocrinologists should not overemphasize this single measurement. The evaluation of rapid physical changes and determination of when to proceed with GnRHST should be carefully determined by clinicians. GnRHST may also be indicated when clinical examinations disagree with $\mathrm{mLH}$ measurement.

Our results also demonstrate that BMI is not associated with positive response after GnRHST. Body composition changes over the course of puberty, and both lean body mass and fat mass increase. Obesity during childhood may lead to early signs of puberty (thelarche) in girls, ${ }^{38)}$ but BMI measured as a ratio of weight $(\mathrm{kg})$ to the height squared $(\mathrm{m})$ was not useful for CPP diagnosis $(P=0.43)$. Increased juvenile obesity can be confused with breast development and erroneous CPP diagnosis. Therefore, $\mathrm{mLH}$ level is helpful as a first measurable step.

Our study is limited by the small number of patients included and its retrospective nature. For clinical applications, a larger patient sample is needed to determine whether elevated $\mathrm{mLH}$ is specific enough to replace GnRHST.

In conclusion, we demonstrate that morning unstimulated LH with emphasis on appropriate sampling time predicts positive results for GnRHST. The $\mathrm{mLH}$ is a useful screening tool for the diagnosis of CPP. Observations of advanced BA vs. CA and BMI, in isolation, are not helpful in screening for CPP.

\section{Ethical statement}

This study was approved by the Institutional Review Board (IRB) of National Health Insurance Service Ilsan Hospital (approval number: SUYON 2014-169). Informed consent was exempted by the IRB.

\section{Conflict of interest}

No potential conflict of interest relevant to this article was reported.

\section{References}

1. Carel JC, Eugster EA, Rogol A, Ghizzoni L, Palmert MR; ESPE-LWPES GnRH Analogs Co analogs nsensus Conference Group, et al. Consensus statement on the use of gonadotropin-releasing hormone in children. Pediatrics 2009;123:e752-62.

2. Lee PA. Central precocious puberty. An overview of diagnosis, treatment, and outcome. Endocrinol Metab Clin 
North Am 1999;28:901-18, xi.

3. Boyar R, Finkelstein J, Roffwarg H, Kapen S, Weitzman E, Hellman L. Synchronization of augmented luteinizing hormone secretion with sleep during puberty. N Engl J Med 1972;287:582-6.

4. Aksglaede L, Sørensen K, Petersen JH, Skakkebaek NE, Juul A. Recent decline in age at breast development: the Copenhagen Puberty Study. Pediatrics 2009;123:e932-9.

5. Kim SH, Huh K, Won S, Lee KW, Park MJ. A significant increase in the incidence of central precocious puberty among Korean girls from 2004 to 2010. PLoS One 2015; 10:e0141844.

6. Lee PA. Laboratory monitoring of children with precocious puberty. Arch Pediatr Adolesc Med 1994;148:369-76.

7. Brook CG. Precocious puberty. Clin Endocrinol (Oxf) 1995;42:647-50.

8. Gaspari L, Paris F, Jeandel C, Sultan C. Peripheral precocious puberty in a 4-month-old girl: role of pesticides? Gynecol Endocrinol 2011;27:721-4.

9. Paris F, Gaspari L, Servant N, Philibert P, Sultan C. Increased serum estrogenic bioactivity in girls with premature thelarche: a marker of environmental pollutant exposure? Gynecol Endocrinol 2013;29:788-92.

10. Johnson GF, Dorst JP, Kuhn JP, Roche AF, Dávila GH. Reliability of skeletal age assessments. Am J Roentgenol Radium Ther Nucl Med 1973;118:320-7.

11. King DG, Steventon DM, O'Sullivan MP, Cook AM, Hornsby VP, Jefferson IG, et al. Reproducibility of bone ages when performed by radiology registrars: an audit of Tanner and Whitehouse II versus Greulich and Pyle methods. Br J Radiol 1994;67:848-51.

12. Lynnerup N, Belard E, Buch-Olsen K, Sejrsen B, DamgaardPedersen K. Intra- and interobserver error of the GreulichPyle method as used on a Danish forensic sample. Forensic Sci Int 2008;179:242.e1-6.

13. van Rijn RR, Lequin MH, Robben SG, Hop WC, van Kuijk C. Is the Greulich and Pyle atlas still valid for Dutch Caucasian children today? Pediatr Radiol 2001;31:748-52.

14. Brito VN, Batista MC, Borges MF, Latronico AC, Kohek $\mathrm{MB}$, Thirone AC, et al. Diagnostic value of fluorometric assays in the evaluation of precocious puberty. J Clin Endocrinol Metab 1999;84:3539-44.

15. Garnier PE, Chaussain JL, Binet E, Schlumberger A, Job JC. Effect of synthetic luteinizing hormone-releasing hormone (LH-RH) on the release of gonadotrophins in children and adolescents. VI. Relations to age, sex and puberty. Acta Endocrinol (Copenh) 1974;77:422-34.

16. Roth JC, Kelch RP, Kaplan SL, Grumbach MM. FSH and LH response to luteinizing hormone-releasing factor in prepubertal and pubertal children, adult males and patients with hypogonadotropic and hypertropic hypogonadism. J Clin Endocrinol Metab 1972;35:926-30.

17. Lee DS, Ryoo NY, Lee SH, Kim S, Kim JH. Basal luteinizing hormone and follicular stimulating hormone: is it sufficient for the diagnosis of precocious puberty in girls? Ann
Pediatr Endocrinol Metab 2013;18:196-201.

18. Pasternak Y, Friger M, Loewenthal N, Haim A, Hershkovitz E. The utility of basal serum LH in prediction of central precocious puberty in girls. Eur J Endocrinol 2012;166:2959.

19. Jakacki R, Kelch RP, Sauder SE, Lloyd JS, Hopwood NJ, Marshall JC. Pulsatile secretion of luteinizing hormone in children. J Clin Endocrinol Metab 1982;55:453-8.

20. Wu FC, Butler GE, Kelnar CJ, Huhtaniemi I, Veldhuis JD. Ontogeny of pulsatile gonadotropin releasing hormone secretion from midchildhood, through puberty, to adulthood in the human male: a study using deconvolution analysis and an ultrasensitive immunofluorometric assay. J Clin Endocrinol Metab 1996;81:1798-805.

21. Apter D, Bützow TL, Laughlin GA, Yen SS. Gonadotropinreleasing hormone pulse generator activity during pubertal transition in girls: pulsatile and diurnal patterns of circulating gonadotropins. J Clin Endocrinol Metab 1993;76:940-9.

22. Kang YS, Yoo DY, Chung IH, Yoo EG. Diurnal variation of gonadotropin levels in girls with early stages of puberty. Ann Pediatr Endocrinol Metab 2017;22:183-8.

23. Kim JR, Lee YS, Yu J. Assessment of bone age in prepubertal healthy Korean children: comparison among the Korean standard bone age chart, Greulich-Pyle method, and Tanner-Whitehouse method. Korean J Radiol 2015;16:201 5.

24. Greulich WW, Pyle SI. Radiographic atlas of skeletal development of the hand and wrist. 2nd ed. Stanford (CA): Stanford University Press, 1999.

25. Youden WJ. Index for rating diagnostic tests. Cancer 1950;3:32-5.

26. Brauner R, Adan L, Malandry F, Zantleifer D. Adult height in girls with idiopathic true precocious puberty. J Clin Endocrinol Metab 1994;79:415-20.

27. Golub MS, Collman GW, Foster PM, Kimmel CA, RajpertDe Meyts E, Reiter EO, et al. Public health implications of altered puberty timing. Pediatrics 2008;121 Suppl 3:S21830.

28. Abreu AP, Dauber A, Macedo DB, Noel SD, Brito VN, Gill $\mathrm{JC}$, et al. Central precocious puberty caused by mutations in the imprinted gene MKRN3. N Engl J Med 2013;368:246775.

29. Bourguignon JP, Franssen D, Gérard A, Janssen S, Pinson A, Naveau E, et al. Early neuroendocrine disruption in hypothalamus and hippocampus: developmental effects including female sexual maturation and implications for endocrine disrupting chemical screening. J Neuroendocrinol 2013;25:1079-87.

30. Gajdos ZK, Hirschhorn JN, Palmert MR. What controls the timing of puberty? An update on progress from genetic investigation. Curr Opin Endocrinol Diabetes Obes 2009;16:16-24.

31. Wierson M, Long PJ, Forehand RL. Toward a new understanding of early menarche: the role of environmental stress 
in pubertal timing. Adolescence 1993;28:913-24.

32. Marshall WA, Tanner JM. Variations in pattern of pubertal changes in girls. Arch Dis Child 1969;44:291-303.

33. Varimo T, Huttunen H, Miettinen PJ, Kariola L, Hietamäki J, Tarkkanen A, et al. Precocious puberty or premature thelarche: analysis of a large patient series in a single tertiary center with special emphasis on 6- to 8-year-old girls. Front Endocrinol (Lausanne) 2017;8:213.

34. Partsch CJ, Heger S, Sippell WG. Management and outcome of central precocious puberty. Clin Endocrinol (Oxf) 2002;56:129-48.

35. Flor-Cisneros A, Roemmich JN, Rogol AD, Baron J.
Bone age and onset of puberty in normal boys. Mol Cell Endocrinol 2006;254-255:202-6.

36. Houk CP, Kunselman AR, Lee PA. Adequacy of a single unstimulated luteinizing hormone level to diagnose central precocious puberty in girls. Pediatrics 2009;123:e1059-63.

37. Oerter KE, Uriarte MM, Rose SR, Barnes KM, Cutler GB Jr. Gonadotropin secretory dynamics during puberty in normal girls and boys. J Clin Endocrinol Metab 1990;71:1251-8

38. Burt Solorzano CM, McCartney CR. Obesity and the pubertal transition in girls and boys. Reproduction 2010;140:399-410. 